Pecvnia, 5 (2007), pp. 107-144

\title{
De La Sorbona a Londres: El camino hacia el Espacio Europeo de Educación Superior (Adaptación en España: especial referencia a los Estudios Económico-Empresariales)
}

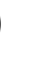


europea, como es el referido a los estudios de carácter económico-empresarial.

Palabras clave: Espacio Europeo de Educación Superior (EEES), Proceso de Bolonia, España, Grado en Economía y Empresa. convergence is given; that is the one referred to the field of business and economic studies.

Key words: European Higher Education Area (EHEA), Bologna Process, Spain, Degree in Economics and Business.

\section{INTRODUCCIÓN}

El sistema universitario español ha experimentado profundas modificaciones en los últimos años, motivadas, no sólo por los cambios sociales que han tenido lugar, sino también, y fundamentalmente, debido al entorno en el que nuestro país está enclavado, en un espacio único europeo.

Entendida, de forma genérica, como la institución educativa encargada de la enseñanza superior, la universidad se ha visto inmersa, en las últimas décadas, en un proceso de profunda transformación, con el fin de responder a las demandas de calidad y alcanzar los niveles de innovación que la sociedad del conocimiento demanda.

Este proceso de transformación ha implicado no sólo a la Universidad Española, sino que ha sido en Europa, considerada la cuna de las universidades, donde se inició el nuevo diseño del escenario universitario actual. Tras los modelos francés, anglosajón o alemán que se habían seguido hasta los años cincuenta, fue en la década de los setenta cuando se produjo un cambio profundo, debido, fundamentalmente, al desarrollo económico de Europa, los cambios demográficos y programáticos de los gobiernos y la extensión del estado del bienestar.

Tras la constitución de la Comunidad Económica Europea, por el Tratado de Roma de 1957, firmado por Francia, Alemania, Italia y los países del Benelux (Bélgica, Holanda y Luxemburgo), con el objetivo de crear un "mercado único" basado en la libertad de circulación de personas, servicios, mercancías y capitales, la creación de una unión aduanera y la elaboración de políticas comunes, el proceso de integración europea ha ido avanzando. Por un lado, han aumentado los países que se han ido adhiriendo, en sucesivos tratados, a la Comunidad, hasta llegar, en la actualidad, a un total de 27 países integrantes de la llamada Unión Europea. Por otro lado, el proceso se ha venido desarrollando en progresivas fases, mediante las que se ha avanzado en la constitución de la unidad europea: creación del gran mercado único europeo, cohesión económica y social entre 
los Estados miembros, armonización de políticas (social, de investigación y desarrollo tecnológico, medio ambiente), e instauración de la moneda única.

Junto a estos programas de convergencia económica y monetaria, la Unión Europea ha diseñado espacios comunes vinculados al ámbito jurídico, social, cultural y educativo, siendo en éste último donde destaca la creación del denominado Espacio Europeo de Educación Superior (EEES), aspecto clave en el proceso de armonización de los sistemas de educación superior a nivel europeo.

\section{LA CREACIÓN DEL ESPACIO EUROPEO DE EDUCACIÓN}

SUPERIOR

El origen del EEES lo podemos situar en la CARTA MAGNA DE LAS UNIVERSIDADES EUROPEAS, firmada en Bolonia el 18 de septiembre de 1988 por un conjunto numeroso de rectores de universidades europeas; de ahí que todo el proceso de convergencia europea en materia de enseñanza superior se conozca como "proceso de Bolonia". Su objetivo fundamental se planteó en términos de una toma de conciencia con relación al papel que las Universidades están llamadas a jugar en una sociedad que se transforma y se internacionaliza. Los principios fundamentales de la misma, que se exponen a continuación, expresan fielmente lo que la universidad debería ser:

1. La universidad, en el seno de sociedades organizadas de forma diversa debido a las diferentes condiciones geográficas e históricas, es una institución autónoma que, de manera crítica, produce y transmite la cultura por medio de la investigación y la enseñanza.

Para abrirse a las necesidades del mundo contemporáneo, debe lograr, en su esfuerzo de investigación y enseñanza, una independencia moral y científica de todo poder político y económico.

2. En las universidades, la actividad docente es indisociable de la actividad investigadora, a fin de que la enseñanza siga tanto la evolución de las necesidades como las exigencias de la sociedad y de los conocimientos científicos.

3. La libertad de investigación, de enseñanza y de formación son el principio fundamental de la vida de las universidades; los poderes públicos y las universidades, cada uno en su esfera de 
competencias, deben garantizar y promover el respeto a esta exigencia fundamental.

El rechazo de la intolerancia y el diálogo permanente hacen de la universidad un lugar de encuentro privilegiado entre profesores, que tienen la capacidad de transmitir el saber y los medios de desarrollarlo mediante la investigación y la innovación, y estudiantes, que tienen el derecho, la voluntad y la capacidad de enriquecerse con ello.

4. Depositaria de la tradición del humanismo europeo, pero con la constante preocupación de atender al saber universal, la universidad, para asumir su misión, ignora toda frontera geográfica o política y afirma la necesidad imperiosa del conocimiento recíproco y de la interacción de las culturas.

\subsection{Declaración de La Sorbona (1998)}

La declaración de intenciones recogida en la Carta Magna tuvo su siguiente reflejo en la llamada DECLARACIÓN DE LA SORBONA de 1998, que firmaron en París los Ministros de Educación de Francia, Reino Unido, Italia y Alemania, con el propósito de armonizar el diseño del sistema de educación superior europeo. Conscientes de la importancia que estaba alcanzando al proceso europeo, destacaron la necesidad de que la creación del espacio europeo no se centrara de modo exclusivo en aspectos económicos y monetarios, sino que alcanzara también a la Europa de los conocimientos, siendo imprescindible el papel de las universidades en la consolidación y desarrollo de las dimensiones intelectuales, culturales, sociales y técnicas del continente europeo.

Para los firmantes de la Declaración, el tiempo de cambios que se avecina respecto a las condiciones educativas y laborales trae consigo una diversificación de las carreras profesionales, siendo la educación y formación continua un pilar fundamental. Por ello, es necesario dar a la sociedad un "sistema de educación superior que les ofrezca las mejores oportunidades para buscar y encontrar su propio ámbito de excelencia".

Esto supone, por otro lado, abrir el área de educación superior, acabando con las fronteras y desarrollando un marco de enseñanza y aprendizaje que favorecerá una movilidad y cooperación más estrechas. Dicho marco se articula en dos aspectos fundamentales: por un lado, un sistema con dos ciclos, grado y postgrado, que, tal como señala el 
documento, servirá de piedra angular a la hora de establecer comparaciones y equivalencias a nivel internacional; por otro lado, la utilización de créditos, como el sistema ECTS (European Credit Transfer System o Sistema Europeo de Transferencia de Créditos) y de semestres, lo que permitirá la convalidación de los créditos cursados por estudiantes en diferentes universidades europeas, ya sea en educación inicial o continua.

Este proceso de armonización de la educación superior en Europa ya se había iniciado el año anterior con la firma del Convenio de Lisboa sobre reconocimiento de cualificaciones ${ }^{1}$ obtenidas en educación superior. El texto, abierto a la firma de los Estados Miembros del Consejo de Europa y de la Región Europa de la UNESCO, así como a otros Estados que pudieran ser invitados, establece el reconocimiento, por cada una de las partes, de las cualificaciones de educación superior y de las que dan acceso a dichos estudios conferidas en otra parte, junto al reconocimiento de los periodos de estudios cursados en el marco de un programa de educación superior en alguna de las partes.

No obstante, este primer paso en la armonización debe continuarse, por lo que los Ministros firmantes de la Declaración de La Sorbona se comprometen a la promoción de un marco común de referencia dirigido a mejorar el reconocimiento externo y a facilitar la movilidad estudiantil y las oportunidades de empleo, creando un Área o Espacio Europeo de Educación Superior, donde las identidades nacionales y los intereses comunes puedan relacionarse y reforzarse en beneficio de Europa, de sus estudiantes y de los ciudadanos en general. A su vez, llaman a otros Estados Miembros de la Unión Europea y del resto de Europa para que se unan en esta iniciativa, lo que se plasma en la llamada Declaración de Bolonia.

\subsection{Declaración de Bolonia (1999)}

La DeCLARACIÓN DE BoloniA, firmada en 1999 por los Ministros responsables de educación de 29 Estados europeos, reafirma la adhesión a

Se ha optado por traducir la palabra qualifications del documento original por cualificaciones, por ser éste un concepto más amplio que el término titulaciones habitualmente utilizado. En el presente documento cualificación se define como "cualquier título, diploma u otro certificado emitido por una autoridad competente que da fe de que se han alcanzado unos resultados de aprendizaje, normalmente tras haber completado con éxito un plan de estudios de educación superior reconocido". 
los principios generales que subyacen en la Declaración de La Sorbona, a la vez que sienta las bases para la construcción de un Espacio Europeo de Educación Superior conforme a los principios de calidad, movilidad, diversidad y competitividad.

Se recogen seis objetivos:

- Adopción de un sistema de títulos fácilmente comprensible y comparable, mediante, entre otras medidas, el Suplemento Europeo al Título.

- Adopción de un sistema basado esencialmente en dos ciclos principales. Para acceder al segundo ciclo será preciso haber completado el primer ciclo, éste con una duración mínima de tres años.

- Establecimiento de un sistema común de créditos, como puede ser el sistema ECTS.

- Promoción de la movilidad, para estudiantes, investigadores, profesores y personal administrativo.

- Promoción de la cooperación europea en materia de aseguramiento de la calidad para el desarrollo de criterios y metodologías comparables.

- Promoción de la dimensión europea en la enseñanza superior, especialmente el desarrollo curricular, la cooperación institucional, esquemas de movilidad y programas integrados de estudios, de formación y de investigación.

La Declaración establece como plazo hasta el año 2010 para la realización del EEES, con fases bianuales de realización, que finalizarán con una Conferencia Ministerial, en las que se revisará lo conseguido y se establecerán directrices para el futuro.

2.3. Conferencias Ministeriales de Seguimiento: Praga (2001), Berlín (2003), Bergen (2005) y Londres (2007)

La I Conferencia de Seguimiento del Proceso de Bolonia se celebró en PRAGA el 19 de mayo de 2001. En ella se respaldan las actuaciones realizadas hasta la fecha, y se añaden a los objetivos de Bolonia otros tres: 
- Promover la enseñanza superior permanente para la población adulta en las universidades.

- Incorporar formalmente a los estudiantes en las decisiones sobre el EEES, a través de la Unión Nacional de Estudiantes de Europa (ESIB).

- Promover el atractivo del EEES en todo el mundo mediante el desarrollo de sistemas de garantía de la calidad y de mecanismos de certificación de acreditación.

Con esto se pretende que exista un movimiento hacia la compatibilidad para hacer sistemas de educación superior más transparentes y destacar la calidad de la educación superior europea a nivel nacional e institucional.

El 19 de septiembre de 2003 se celebra en BERLín la II CONFERENCIA DE SEgUimiento. En ésta, se pone el énfasis en la dimensión social de la educación superior, entendida como un bien público. Se acentúan los vínculos investigación-educación superior, incluyendo plenamente los estudios de doctorado en el proceso de Bolonia.

Hasta la siguiente conferencia, a celebrar en el año 2005, se establecen tres prioridades: estructura, calidad y títulos. Asimismo, se comprometen a la organización de los estudios en dos ciclos principales para mejorar el reconocimiento del sistema de grados y periodos de estudios. También se acuerda apoyar el desarrollo de la calidad a niveles institucionales, nacionales y europeos. En este sentido, los sistemas de garantía nacionales deben reunir las siguientes condiciones:

- Definición de las responsabilidades de órganos e instituciones involucrados.

- Evaluación de los programas o instituciones, incluyendo asesoramiento interno, revisiones externas, participación de estudiantes y publicación de los resultados.

- Sistema de acreditación, certificación o procedimientos similares.

- Participación internacional, cooperación y trabajo en red (networking). 
Los ministros reunidos en Berlín se reafirman en la movilidad, con el propósito firme de superar los obstáculos todavía existentes y con el reconocimiento de la importancia de completar estudios con estancias en el extranjero en programas conjuntos.

Por primera vez, se considera el aprendizaje a lo largo de la vida (longlife learning o sus siglas LLL) como parte integral del de la Educación Superior, a la vez que se reconoce la participación activa de universidades y estudiantes en el proceso de convergencia. Y se refuerza la promoción exterior en la Educación Superior Europea.

En el año 2005, concretamente en BERGEN los días 19 y 20 de mayo, tuvo lugar la siguiente CONFERENCIA BIENAL DE MINISTROS, con la participación de 45 países. El comunicado va dirigido a la puesta en marcha del Espacio Europeo de Educación Superior o European Higher Education Area (EHEA), con la intención de definir estándares comunes de calidad, los marcos de reconocimiento de títulos y la flexibilidad de acceso.

Los principales aspectos abordados fueron los siguientes:

- Importancia de la mayor implicación y compromiso por parte de las universidades, su profesorado y sus estudiantes, en la implantación de los nuevos planes de estudio y las nuevas metodologías.

- El avance que se aprecia en las áreas señaladas en Berlín: el sistema de titulaciones, el aseguramiento de la calidad y el reconocimiento de títulos y periodos de estudio.

- Establecimiento del marco general europeo de cualificaciones y titulaciones de educación superior en tres ciclos.

- La estructura cíclica se debe asentar poniendo énfasis en la adecuada definición y evaluación de los resultados del aprendizaje y las competencias a adquirir en todos los títulos de grado y máster (postgrado).

- El refuerzo al diálogo entre los gobiernos, los empleadores y los agentes sociales para la mejora del empleo de los graduados universitarios, en especial los de primer ciclo (Grado-Bachelor).

- La eliminación de obstáculos para el acceso a los nuevos estudios de máster, desde los estudios de grado, garantizando la igualdad de oportunidades. 
- La cooperación entre las agencias de calidad de los distintos países para avanzar en la definición de criterios comunes para la evaluación, la acreditación de los estudios y su mutuo reconocimiento.

- La eliminación de obstáculos que subsisten para el reconocimiento de títulos y periodos de estudio entre las instituciones de educación superior europeas (Cumplimiento de la Convención de Lisboa).

- Mejora del reconocimiento de programas de aprendizaje previos para el acceso a la educación superior y de la conexión de ésta con el aprendizaje continuado (LLL).

- El énfasis en el papel de las universidades para el mejor desarrollo de la investigación, la innovación y la mayor coordinación entre el EEES y el Espacio Europeo de Investigación.

- El EEES debe propiciar el incremento del número de doctorandos, que deben considerarse tanto estudiantes como investigadores en formación.

- La dimensión de la educación superior debe mejorar la accesibilidad, la igualdad de oportunidades y las condiciones de acogida.

- El atractivo internacional de la educación superior europea y el incremento de relaciones con instituciones y gobiernos de otros ámbitos geográficos.

- La movilidad de estudiantes y profesores sigue resaltándose como elemento fundamental del EEES.

En resumen, en la conferencia de Bergen se sintetizan todas las actividades y líneas de trabajo desarrolladas desde la celebración de la conferencia de Berlín, dando prioridad al desarrollo de los siguientes puntos:

- La estructura de titulaciones en tres etapas en cada país participante.

- Sistemas de garantía de calidad nacionales que cooperen con redes europeas.

- Reconocimiento mutuo de títulos y periodos de estudio entre los países participantes. 
La última CONFERENCIA DE MINISTROS DE EdUCACIÓN se ha celebrado en LONDRES los días 17 y 18 de mayo de 2007 y en ella ha participado, junto con los 45 países que se habían reunido en Bergen, la República de Montenegro.

En primer lugar, se hace un balance del proceso de convergencia europea desde la Conferencia de Bergen, señalando que se han realizado avances positivos en la materialización del EEES, basado en la autonomía institucional, la libertad académica, la igualdad de oportunidades y los principios democráticos, lo que facilitará la movilidad, aumentará la empleabilidad y fortalecerá el atractivo y la competitividad de Europa. En este sentido, los países firmantes del Comunicado resultante de la Conferencia de Londres reiteran su compromiso de aumentar la compatibilidad y comparabilidad de sus sistemas de educación superior, con el fin de garantizar que el EEES mantenga la competitividad y responda con eficacia a los retos de un mundo globalizado.

En cuanto a los aspectos concretos relativos a la creación del EEES, en el Comunicado de Londres se señala lo siguiente:

- Movilidad de personal, estudiantes y titulados: es preciso eliminar los obstáculos a la movilidad relacionados con la inmigración, el reconocimiento de títulos y diplomas, los incentivos económicos insuficientes o las disposiciones rígidas sobre jubilación. En este sentido, es necesaria la responsabilidad de los Gobiernos para facilitar la entrega de visados y permisos de residencia y trabajo, así como un incremento de los programas conjuntos y la creación de planes de estudio flexibles, como mecanismos para incentivar la movilidad, procurando que sea más equilibrada entre los países en todo el EEES.

- Estructura de los estudios en tres ciclos: aunque se han producido avances significativos en este punto, tanto a nivel estatal como institucional, aumentando de una forma considerable el número de alumnos matriculados en los cursos de los dos primeros ciclos, así como los programas de doctorado estructurados, es necesario seguir progresando en la eliminación de las barreras al acceso y a la progresión entre ciclos y en una implementación adecuada de los créditos ECTS basados en los resultados del aprendizaje y en la carga de trabajo del estudiante.

- Reconocimiento: para fomentar la movilidad de los ciudadanos y garantizar de manera permanente el atractivo y competitividad del 
EEES, es fundamental el correcto reconocimiento de cualificaciones en la educación superior y de periodos de estudio y aprendizaje previo, incluyendo el aprendizaje informal y no formal.

- Marcos de cualificaciones: son instrumentos fundamentales para lograr la comparabilidad y la transparencia dentro del EEES, así como para facilitar el trasvase dentro y entre los sistemas de educación superior. En este sentido, los países firmantes del Comunicado se comprometen a poner en práctica, en el año 2010, los marcos nacionales de cualificaciones, acreditados por el modelo global del Marco de Cualificaciones del EEES y compatibles con la propuesta de la Comisión Europea sobre el Marco Europeo de Cualificaciones para el aprendizaje a lo largo de la vida.

- Aprendizaje a lo largo de la vida: para avanzar en este punto, es preciso desarrollar itinerarios de aprendizaje más flexibles, con el fin de respaldar el aprendizaje permanente desde etapas más tempranas. Asimismo, debe fomentarse la comprensión del papel que la educación superior ejerce en la formación a lo largo de la vida.

- Certificación de la calidad y Registro Europeo de Agencias de Calidad: todos los países implicados en el Proceso de Bolonia han comenzado a poner en práctica los Criterios y Directrices para el Aseguramiento de la Calidad en el EEES adoptados en Bergen, con algunos progresos considerables, como la certificación externa de la calidad, el reconocimiento mutuo de la acreditación o las decisiones de mejora de la calidad. El establecimiento de un Registro Europeo de Agencias Certificadoras facilitará el acceso libre a información objetiva sobre las agencias de calidad de confianza que trabajan de acuerdo con las Directrices establecidas.

- Doctorandos: otro objetivo importante lo constituye el acercamiento entre el EEES y el Espacio Europeo de Investigación, en cuya consecución hay que seguir avanzando, mediante el desarrollo y mantenimiento de una amplia variedad de programas de doctorado ligados al modelo global del Marco de Cualificaciones del EEES.

- Dimensión social: otro aspecto a resaltar es la dimensión social de la educación superior, dado que ésta debería jugar un papel esencial en la promoción de la cohesión social, en la reducción de las desigualdades y en la elevación del nivel de conocimiento, 
destrezas y competencias en el seno de la sociedad. Para alcanzar este objetivo, es importante que los estudiantes puedan completar sus estudios sin obstáculos relacionados con su situación socioeconómica y sobre la base de la igualdad de oportunidades.

Como conclusión, los países participantes adoptan la estrategia "El EEES en un escenario global", trabajando en las áreas fundamentales: mejora de la información sobre el EEES, fomento del atractivo y la competitividad del EEES, fortalecimiento de la cooperación basada en la igualdad de las partes, intensificación del diálogo sobre las políticas a desarrollar y mejora del reconocimiento de cualificaciones.

Figura 1: Cronología del proceso de creación del Espacio Europeo de Educación Superior

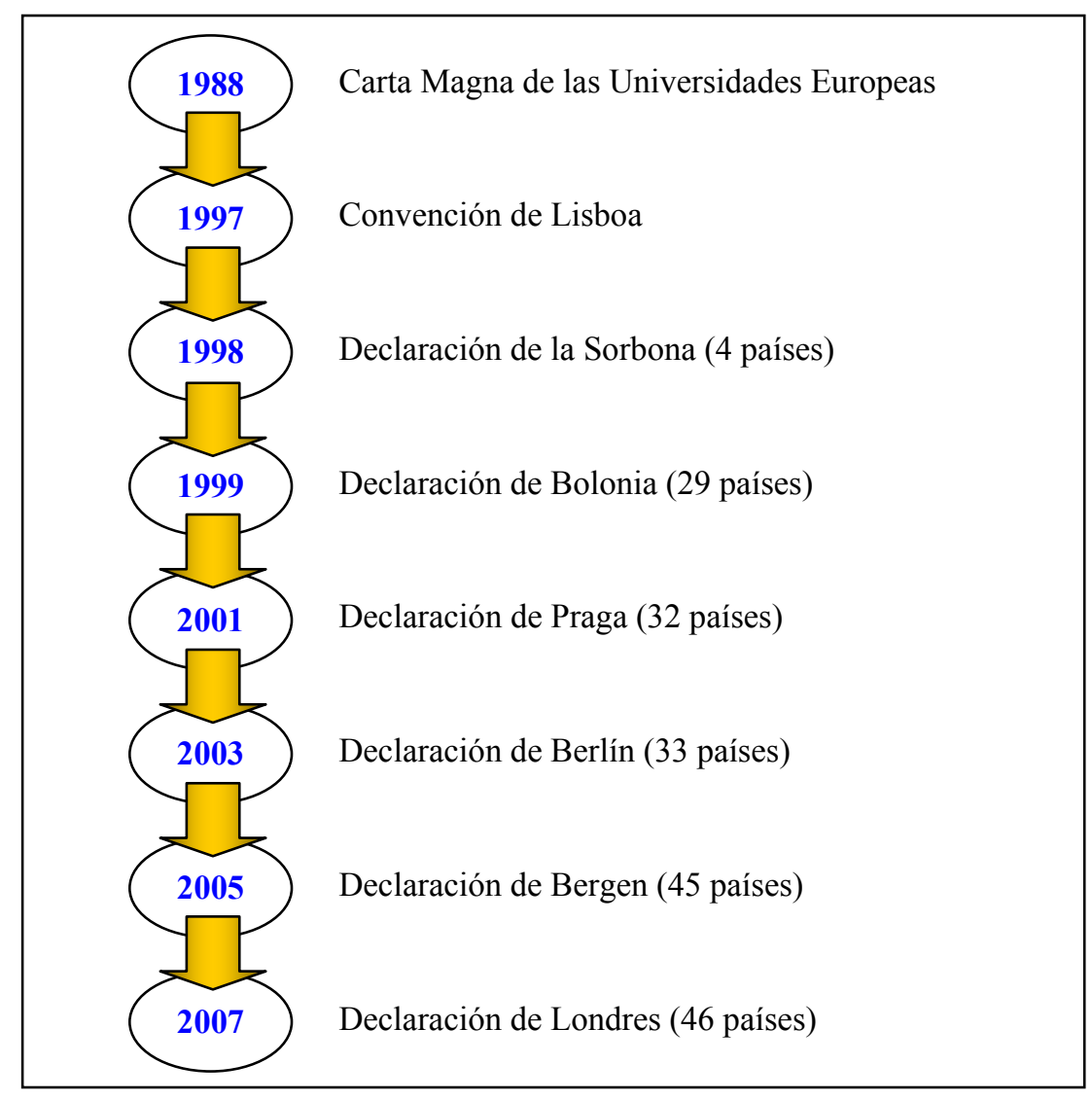

Fuente: Elaboración propia. 
De cara a la siguiente reunión de los Ministros de Educación a celebrar en abril de 2009 en Benelux, se establecen como prioridades la estructura de estudios en tres ciclos, la garantía de calidad y el reconocimiento de los títulos y otros periodos de estudio. Además, se fijan otras prioridades en áreas particulares como el fomento de la movilidad de estudiantes y personal, las acciones y medidas para evaluar la eficacia de la dimensión social de la educación superior, la mejora de la disponibilidad de datos, en cuanto a los dos aspectos anteriores, en todos los países participantes en el Proceso de Bolonia y el incremento de la empleabilidad en cada uno de los tres ciclos en que se estructura el sistema, así como en el contexto del aprendizaje a lo largo de la vida.

Asimismo, siendo el año 2010 una fecha crucial en el proceso de convergencia europea, puede representar una oportunidad para redefinir la visión que motivó la puesta en marcha del Proceso de Bolonia en 1999, por lo que en la primera mitad de 2008 se tomará una decisión sobre el carácter, contenido y lugar de una Cumbre Ministerial que se celebrará en 2010 y en la que se evaluarán los avances globales del proceso desde 1999 hasta el establecimiento del EEES.

En la Figura 1 presentamos la cronología que permite resumir el proceso de creación del EEES, a partir de las diferentes reuniones que han celebrado y de las que han resultado los documentos cuyo contenido acabamos de desarrollar.

\section{EL PROCESO DE BOLONIA EN ESPAÑA}

España, como integrante de la Unión Europa, no ha sido ajena al proceso de armonización de los sistemas nacionales de educación superior descrito. No obstante, los cambios producidos en las últimas décadas en el sistema universitario español han sido propiciados también por otras razones, como los fenómenos demográficos o las nuevas demandas sociales.

Todo ello trajo consigo la obsolescencia de la legislación universitaria existente, lo que impulsó la aprobación de la Ley Orgánica 6/2001, de 21 de diciembre, de Universidades (LOU), modificada por la Ley Orgánica 4/2007, de 12 de abril, con la que se pretende lograr una adaptación a las exigencias del entorno, así como solucionar los problemas más importantes de la universidad española, con el fin de hacer frente a las nuevas demandas de la sociedad. 
No obstante, el gran reto al que se enfrenta la Universidad española es la adaptación al proceso de convergencia para su integración en el EEES.

Para lograr esa adaptación, se establece un título propio en la LOU dedicado al Espacio Europeo de Enseñanza Superior (Título XIII), donde se dispone lo siguiente:

- Se adoptarán las medidas necesarias para completar la plena integración del sistema español en el espacio europeo de enseñanza superior (Art. 87).

- Se adoptarán las medidas que aseguren que los títulos oficiales expedidos por las Universidades españolas se acompañen del Suplemento Europeo al Título (Art. 88.1).

- Se establecerán las medidas necesarias para adoptar el sistema europeo de créditos (Art. 88.2).

- Se fomentará la movilidad de los estudiantes en el espacio europeo de enseñanza superior a través de programas de becas, ayudas y créditos al estudio (Art. 88.3), la movilidad de profesores (Art. 89.4) y la de personal de administración y servicios (Art. 89bis añadido por la Ley 4/2007).

La ley legitima al gobierno para realizar los desarrollos más adecuados cuando lo considere oportuno, abre expectativas de cambios pero sin establecer con precisión el cómo y cuándo.

El Documento-Marco sobre la integración del sistema universitario español en el EEES, elaborado por el Ministerio de Educación, Cultura y Deporte en febrero de 2003, inicia los debates necesarios para definir el cómo y, por tanto, establece el punto de partida del cuándo.

El proceso seguido en España, en orden cronológico, es el siguiente:

- Durante los años 2001-2002, se crean la Agencia Nacional de Evaluación de la Calidad y Acreditación (ANECA) y los órganos de evaluación en las Comunidades Autónomas, en cumplimiento con lo establecido en la LOU, cuya misión es la coordinación y dinamización de las políticas de gestión de la calidad en las universidades españolas. 
- De acuerdo con el artículo 87 de la LOU, el Real Decreto 1044/2003, de 1 de agosto, establece el procedimiento para la expedición por las universidades del Suplemento Europeo al Título. La implantación del Suplemento al Título en España se plantea en dos fases, una primera experimental con "Experiencias piloto", y una segunda definitiva, una vez incorporado al sistema universitario español el sistema de créditos europeo.

- El Real Decreto 1125/2003, de 5 de septiembre, establece el sistema europeo de créditos y el sistema de calificaciones en las titulaciones de carácter oficial y validez en todo el territorio nacional. El crédito europeo (ECTS) nace con los programas de movilidad de estudiantes, fundamentalmente Sócrates/Erasmus, para dar solución a la necesidad de encontrar un sistema de equivalencias y de reconocimiento de los estudios cursados en otros países. El crédito europeo se define como "la unidad de medida del haber académico que representa la cantidad de trabajo del estudiante para cumplir los objetivos del programa de estudios y que se obtiene por la superación de cada una de la materias que integran los planes de estudios de las diversas enseñanzas conducentes a la obtención de títulos universitarios de carácter oficial y validez en todo el territorio nacional" (Art. 3).

- En el año 2004, se publica el Real Decreto 49/2004, de 19 de enero, con la finalidad de desarrollar la homologación de planes de estudios y títulos de carácter oficial y validez en todo el territorio nacional.

- Durante el 2005 se procedió a la definición del marco general de los Estudios de Primer y Segundo Ciclos, Grado y Postgrado, aprobándose dos Reales Decretos, en los que se establecían las primeras líneas maestras sobre la estructura a seguir por las enseñanzas universitarias de Grado y Postgrado, atendiendo a lo establecido en la Conferencia de Ministros Europeos de Educación Superior de Bergen.

- No obstante, el proceso se paralizó, debido a los cambios producidos en el Ministerio de Educación y Ciencia, que culminaron con el nombramiento de una nueva Ministra, el 7 de abril de 2006. Con este nombramiento, el proceso de adaptación del sistema universitario español al proceso de convergencia europea adquirió nuevo dinamismo, contemplando como uno de sus objetivos principales el impulso a la dimensión europea e internacional de la universidad española. De esta manera, el Ministerio publicó, el 26 de septiembre de ese año, una propuesta sobre la organización de las enseñanzas universitarias en España, al objeto de culminar el proceso de construcción del EEES. En el mismo se recoge un calendario de 
aplicación, con el fin de que los nuevos Grados comiencen a impartirse en el curso 2008-09, aunque el calendario establecido ha sufrido modificaciones sobre la previsión inicial, resultando el que figura en la Tabla 1.

Tabla 1: Calendario de aplicación del proceso de adaptación del sistema universitario español al EEES

\begin{tabular}{|c|c|}
\hline Septiembre 2006 & $\begin{array}{l}\text { Presentación del documento de trabajo "La organización de las enseñanzas } \\
\text { universitarias en España" }\end{array}$ \\
\hline Noviembre 2006 & $\begin{array}{l}\text { Presentación de un documento de trabajo de aclaraciones sobre el documento } \\
\text { anterior } \\
\text { Debate e informe del CCU sobre el documento "La organización de las enseñanzas } \\
\text { universitarias en España" (Sesión de } 14 \text { de noviembre) }\end{array}$ \\
\hline Diciembre 2006 & $\begin{array}{l}\text { Propuesta de Directrices para la elaboración de títulos universitarios de Grado y } \\
\text { Máster }\end{array}$ \\
\hline $\begin{array}{l}\text { Diciembre } 2006 \text { a } \\
\text { marzo } 2007\end{array}$ & Debate sobre borradores anteriores \\
\hline Febrero 2007 & $\begin{array}{l}\text { Materias básicas por ramas (Anexo del documento de Directrices para la } \\
\text { elaboración de títulos universitarios de Grado y Máster) }\end{array}$ \\
\hline Abril 2007 & $\begin{array}{l}\text { Aprobación de la Ley Orgánica de Modificación de la LOU } \\
\text { Informe del CCU "Financiación del Sistema Universitario Español" }\end{array}$ \\
\hline Mayo 2007 & $\begin{array}{l}\text { Propuesta y debate de decretos } \\
\text { Enseñanzas de Grado y Postgrado } \\
\text { Directrices para la elaboración de títulos } \\
\text { Directrices propias de títulos de profesiones reguladas } \\
\text { Registro de Universidades, Centros y Títulos (Publicado proyecto) } \\
\text { Homologación de títulos } \\
\text { Procedimiento de acreditación nacional } \\
\text { Concursos de acceso a Cuerpos Docentes Universitarios } \\
\text { Estatuto del PDI } \\
\text { Conferencia General de Política Universitaria } \\
\text { Consejo de Universidades (CU) } \\
\text { Creación de Centros y Universidades }\end{array}$ \\
\hline Octubre 2007 & $\begin{array}{l}\text { Aprobación de Decretos } \\
\text { Ordenación de las enseñanzas universitarias oficiales } \\
\text { Procedimiento de acreditación nacional } \\
\text { Concursos de acceso a Cuerpos Docentes Universitarios }\end{array}$ \\
\hline Noviembre 2007 & Inicio de elaboración de planes de estudio por las Universidades \\
\hline Diciembre 2007 & $\begin{array}{l}\text { Directrices propias de títulos de profesiones reguladas } \\
\text { Arquitectura y Arquitectura Técnica } \\
\text { Maestro en Educación Infantil y en Educación Primaria } \\
\text { Profesor de Educación Secundaria Obligatoria y Bachillerato, } \\
\text { Formación Profesional y Enseñanzas de Idiomas. } \\
\text { Médico } \\
\text { Veterinario }\end{array}$ \\
\hline $\begin{array}{l}\text { Hasta mayo } 2008 \\
(\text { para curso 2008-09) }\end{array}$ & $\begin{array}{l}\text { Aprobación de las CC.AA., Informe del CU y aprobación por Consejo de } \\
\text { Ministros e inscripción en el Registro }\end{array}$ \\
\hline Mayo 2008 & Oferta de plazas de nuevos títulos \\
\hline Curso 2008-09 & Comienzo de los nuevos Grados \\
\hline Julio 2012 & Primeros Graduados de nuevos títulos \\
\hline
\end{tabular}


En la propuesta se establece la estructura general de las enseñanzas en tres ciclos, correspondientes a tres niveles de cualificación universitaria denominados Grado, Máster y Doctor, en consonancia con el Marco Europeo de Cualificaciones para la educación superior ${ }^{2}$ resultante de la Conferencia de Bergen. La estructura debe organizarse de modo que se provea tanto la formación universitaria inicial como la formación permanente (a lo largo de la vida), por lo que deben ofertarse enseñanzas orientadas a la primera, a la segunda o a ambas simultáneamente. En este sentido, los estudios correspondientes a los tres ciclos mencionados podrán ser parte de la oferta de formación permanente de la universidad, para lo cual se fijarán horarios y modalidades de estudio que faciliten la participación de estudiantes de distintas características, pudiendo desarrollarse también programas específicos de formación permanente con otros tipo de denominación, como pudiera ser la de Experto o Especialista.

Siguiendo lo recogido en este documento de trabajo, será el Gobierno el que establezca las directrices generales que estructuren los títulos de Grado, Máster y Doctor, así como las directrices para la elaboración de títulos, de acuerdo con las cuales, cada Universidad diseñará los planes de estudios para otorgar un título.

- La propuesta de directrices para la elaboración de títulos universitarios se recoge en un documento de trabajo elaborado por el Ministerio de Educación y Ciencia y publicado el 21 de diciembre de 2006. Continuando con lo señalado en el documento de 26 de septiembre, se establece que los nuevos títulos adaptados a tales directrices comenzarán a implantarse en el curso 2008-09. En este sentido, en el curso 2010-11 no podrán ofertarse plazas de nuevo ingreso en las actuales titulaciones, es decir, Licenciado, Diplomado, Arquitecto, Ingeniero, Arquitecto Técnico e Ingeniero Técnico, en cumplimiento con los compromisos adquiridos por el Gobierno español en la Declaración de Bolonia. No obstante, todos los estudiantes matriculados en las titulaciones anteriores mantendrán el derecho a finalizar sus estudios en las condiciones en que comenzaron.

\footnotetext{
El Marco de Cualificaciones está basado en los denominados "Descriptores de Dublín", surgidos en un Seminario celebrado en esa ciudad el 15 de febrero de 2002, que enuncian genéricamente las expectativas típicas respecto a los objetivos comunes, logros y habilidades que deben alcanzarse para cualquier tipo de programa que otorgue un título de primer, segundo o tercer ciclo. Con ellos, se trata de identificar la naturaleza de la titulación completa, aunque no se pretende que sean descriptivos. Tampoco son exhaustivos ni específicos para cada materia ni están limitados a las áreas académica, profesional o vocacional.
} 
El documento establece las directrices para elaborar propuestas de títulos universitarios de Grado y Máster, así como la documentación que han de presentar las universidades. En este sentido, el plan de estudios se concibe como un proyecto de implantación de una enseñanza universitaria, por lo que no debe limitarse a recoger la mera descripción de los contenidos formativos (los actuales descriptores y las áreas de conocimiento vinculadas), sino que debe incluir también elementos tales como justificación, objetivos, planificación, recursos o resultados previstos.

- El debate de los documentos de trabajo elaborados por el MEC en el seno de la CRUE y del Consejo de Coordinación Universitaria ha dado lugar a un Real Decreto por el que se establece la ordenación de las enseñanzas universitarias oficiales, que ha sido publicado en octubre de 2007 (BOE $n^{\circ} 260$, de 30 de octubre) y que desarrollamos a continuación.

\section{Real Decreto 1393/2007, de 29 de octubre}

El mencionado Decreto tiene por objeto establecer la estructura de las enseñanzas universitarias oficiales, de acuerdo con las líneas generales emanadas del Espacio Europeo de Educación Superior, siendo de aplicación a la ordenación, verificación y acreditación de las enseñanzas oficiales de Grado, Máster y Doctorado, esto es, los tres ciclos ya recogidos en los documentos de trabajo elaborados por el MEC, de acuerdo con lo establecido en la Conferencia de Bergen.

Dichas enseñanzas se concretarán en planes de estudios que serán elaborados por las universidades, verificados posteriormente por el Consejo de Universidades y autorizados por la correspondiente Comunidad Autónoma, de acuerdo con el proceso descrito en la Figura 2.

Para la elaboración de los planes de estudios, las universidades deberán seguir las directrices que establece el Decreto para el diseño de los títulos oficiales correspondientes a los tres ciclos en que se estructuran las enseñanzas universitarias.

Por lo que se refiere a los títulos de GRADO, su finalidad es la obtención por parte del estudiante de una formación general, en una o varias disciplinas, orientada a la preparación para el ejercicio de actividades de carácter profesional, debiendo elaborarse a partir de las siguientes directrices: 
Figura 2: Verificación y acreditación de los títulos

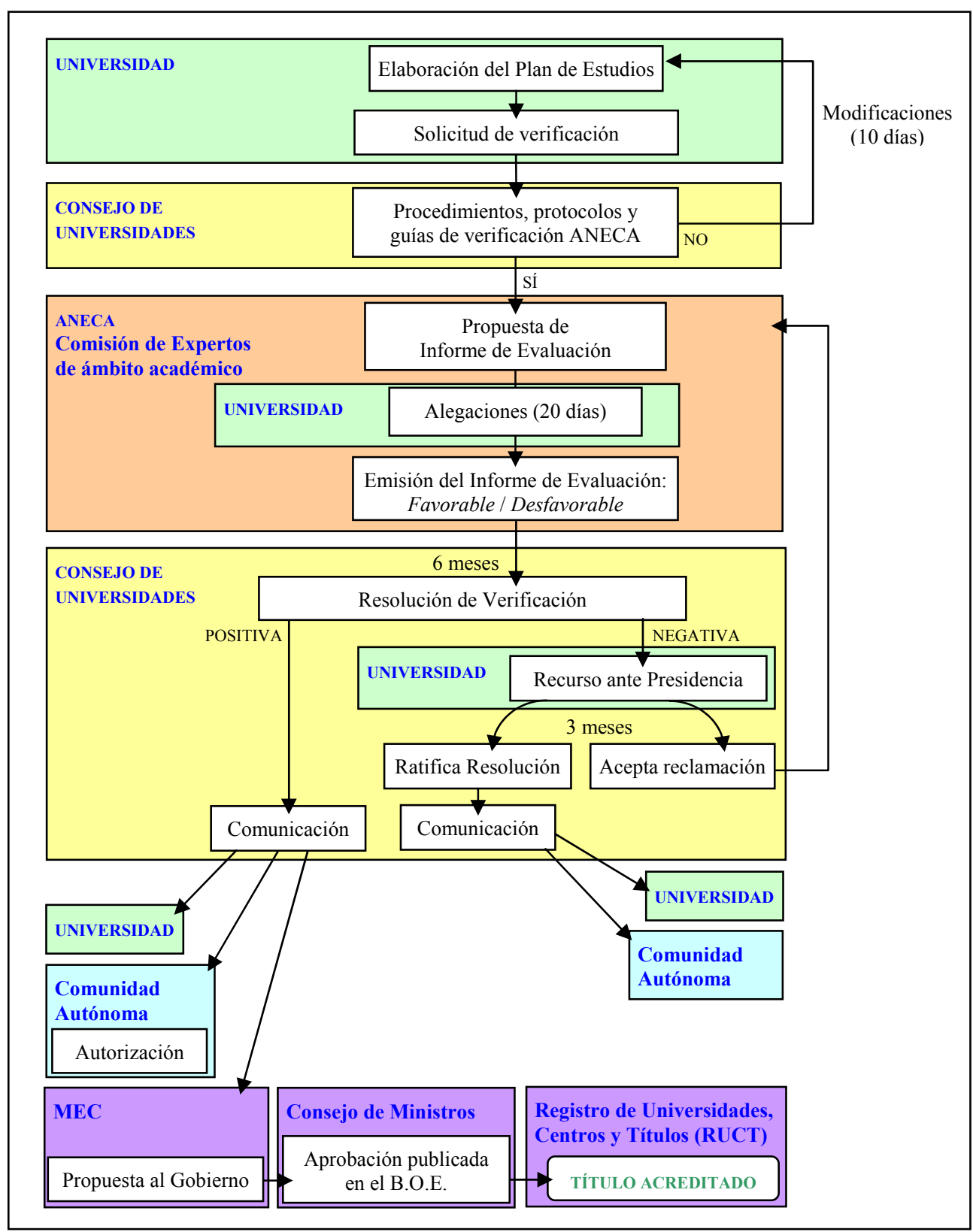

Fuente: Elaboración propia, a partir del capítulo VI del Real Decreto 1393/2007, de 29 de octubre. 
- Los planes de estudios tendrán 240 créditos $^{3}$, que contendrán toda la formación teórica y práctica que el estudiante deba adquirir, incluyendo aspectos básicos de la rama de conocimiento ${ }^{4}$, materias obligatorias u optativas, seminarios, prácticas externas, trabajos dirigidos, trabajo de fin de Grado que el estudiante debe elaborar $\mathrm{y}$ defender $\mathrm{u}$ otras actividades formativas.

- Del contenido del plan de estudios, un mínimo de 60 créditos deberán ser de formación básica, de los cuales al menos 36 deberán estar vinculados a algunas de las materias recogidas en el anexo II del Real Decreto y que se presentan en la Tabla 2, para la rama de conocimiento a la que se quiera adscribir el título. Estas materias se concretarán en asignaturas con una extensión mínima de 6 créditos ECTS y serán ofertadas en la primera mitad del plan de estudios. El resto de créditos deberán estar configurados por materias básicas de la misma u otras ramas de conocimiento o por otras materias, siempre que se justifique su carácter básico para la formación inicial del estudiante o su carácter transversal.

Tabla 2: Materias básicas por ramas de conocimiento

\begin{tabular}{|c|c|c|c|c|}
\hline $\begin{array}{l}\text { ARTES Y } \\
\text { HUMANIDADES }\end{array}$ & CIENCIAS & $\begin{array}{l}\text { CIENCIAS DE LA } \\
\text { SALUD }\end{array}$ & \begin{tabular}{|l|} 
CIENCIAS \\
SOCIALES Y \\
JURÍDICAS
\end{tabular} & $\begin{array}{l}\text { ARQUITECTURA E } \\
\text { INGENIERIAA }\end{array}$ \\
\hline \begin{tabular}{|l} 
Antropología \\
Arte \\
Ética \\
Expresión Artística \\
Filosofía \\
Geografía \\
Historia \\
Idioma Moderno \\
Lengua \\
Lengua Clásica \\
Lingüística \\
Literatura \\
Sociología
\end{tabular} & $\begin{array}{l}\text { Biología } \\
\text { Física } \\
\text { Geología } \\
\text { Matemáticas } \\
\text { Química }\end{array}$ & $\begin{array}{l}\text { Anatomía Animal } \\
\text { Anatomía Humana } \\
\text { Biología } \\
\text { Bioquímica } \\
\text { Estadística } \\
\text { Física } \\
\text { Fisiología } \\
\text { Psicología }\end{array}$ & $\begin{array}{l}\text { Antropología } \\
\text { Ciencia Política } \\
\text { Comunicación } \\
\text { Derecho } \\
\text { Economía } \\
\text { Educación } \\
\text { Empresa } \\
\text { Estadística } \\
\text { Geografía } \\
\text { Historia } \\
\text { Psicología } \\
\text { Sociología }\end{array}$ & \begin{tabular}{|l} 
Empresa \\
Expresión Gráfica \\
Física \\
Informática \\
Matemáticas \\
Química
\end{tabular} \\
\hline
\end{tabular}

Fuente: Real Decreto 1393/2007, de 29 de octubre.

${ }^{3}$ No obstante, en los supuestos en que ello venga determinado por normas de derecho comunitario, el Gobierno, previo informe del Consejo de Universidades, podrá asignar un número mayor de créditos.

${ }^{4}$ La universidad, en la solicitud del título correspondiente, debe solicitar su adscripción a una rama de conocimiento, distinguiéndose cinco: Artes y Humanidades, Ciencias, Ciencias de la Salud, Ciencias Sociales y Jurídicas y, por último, Ingeniería y Arquitectura. 
- Si en el plan de estudios están programadas prácticas externas, su extensión máxima será de 60 créditos, debiendo ofertarse preferentemente en la segunda mitad del plan de estudios.

- Por su parte, el trabajo de fin de Grado, orientado a la evaluación de competencias asociadas al título, tendrá entre 6 y 30 créditos y deberá realizarse en la segunda mitad del plan de estudios.

- Asimismo, los estudiantes podrán obtener reconocimiento académico en créditos por la participación en actividades universitarias culturales, deportivas, de representación estudiantil, solidarias y de cooperación, hasta un máximo de 6 créditos del total del plan de estudios.

- Cuando se trate de títulos que habiliten para el ejercicio de actividades profesionales reguladas, el Gobierno establecerá las condiciones específicas para la adecuación de los correspondientes planes de estudios, que en todo caso deberán ajustarse a la normativa europea aplicable.

Por su parte, la estructura de los títulos de MÁSTER, cuya finalidad es la adquisición de una formación avanzada, de carácter especializado o multidisciplinar, orientada a la especialización académica o profesional, o bien a promover la iniciación en tareas investigadoras, seguirá las siguientes pautas:

- Los planes de estudios tendrán entre 60 y 120 créditos, que comprenderán toda la formación teórica y práctica que el estudiante deba recibir (materias obligatorias, materias optativas, seminarios, prácticas externas, trabajos dirigidos, trabajo de fin de Máster, actividades de evaluación y otras que resulten necesarias según las características propias de cada título).

- Concluirán con la elaboración y defensa pública de un proyecto o trabajo de fin de Máster, que tendrá entre 6 y 30 créditos.

- Para acceder a las enseñanzas oficiales de Máster se exigirá estar en posesión de un título universitario oficial español u otro expedido por una institución de educación superior del EEES, que facultan en el país expedidor del título para el acceso a enseñanzas de Máster. 
Por último, las enseñanzas de DoctoRADo tienen como finalidad la formación avanzada del estudiante en las técnicas de investigación, incluyendo la elaboración y presentación de la correspondiente tesis doctoral, consistente en un trabajo original de investigación, y se organizarán en razón de las siguientes consideraciones:

- El conjunto organizado de actividades formativas y de investigación que conduzcan a la obtención del título de Doctor se estructurará en un Programa de Doctorado, que constará de un periodo de formación y un periodo de investigación.

- Para acceder al periodo de formación del Programa de Doctorado se exigirán los mismos requisitos establecidos para el acceso a las enseñanzas oficiales de Máster. El acceso al periodo de investigación requerirá estar en posesión de un título oficial de Máster Universitario u otro del mismo nivel expedido por una institución de educación superior del EEES, aunque también se recogen otros requisitos de acceso ${ }^{5}$.

Por su parte, en el Anexo I del Decreto se recoge un modelo de Memoria para la solicitud de verificación de Títulos Oficiales, que debe contener los siguientes ELEMENTOS:

1. Descripción del título, con los siguientes aspectos:

a) Denominación.

b) Universidad solicitante y centro responsable de las enseñanzas conducentes al título, o en su caso, departamento o instituto.

c) Tipo de enseñanza (presencial, semipresencial, a distancia...).

d) Número de plazas de nuevo ingreso ofertadas (estimación para los primeros cuatro años).

\footnotetext{
${ }^{5}$ Haber superado 60 créditos incluidos en uno o varios Másteres Universitarios o, de manera excepcional, acreditar 60 créditos de nivel de posgrado que hayan sido configurados, de acuerdo con la normativa de la universidad, por actividades formativas no incluidas en Másteres Universitarios; estar en posesión de un título obtenido conforme a sistemas educativos ajenos al EEES, previa comprobación de que el título acredite un nivel de formación equivalente a los correspondientes títulos españoles de Máster Universitario y que faculta en el país expedidor del título para el acceso a estudios de Doctorado; o bien, estar en posesión de un título de Graduado cuya duración, según normas de derecho comunitario, alcance, al menos, 300 créditos.
} 
e) Número mínimo de créditos europeos de matrícula por estudiante y periodo lectivo y, en su caso, normas de permanencia. Los requisitos fijados deben permitir cursar estudios a tiempo parcial y atender a cuestiones derivadas de la existencia de necesidades educativas especiales.

f) Resto de información necesaria para la expedición del Suplemento Europeo al Título, de acuerdo con la normativa vigente.

2. Justificación, incluyendo los siguientes elementos:

a) Justificación del título propuesto, argumentando el interés académico, científico o profesional del mismo.

b) En el caso de los títulos de Graduado, referentes externos a la universidad proponente que avalen la adecuación de la propuesta a criterios nacionales o internacionales para títulos de similares características académicas, como pueden ser los Libros Blancos del Programa de Convergencia Europea de la ANECA, planes de estudios de otras universidades, informes de asociaciones o colegios profesionales o títulos del catálogo vigentes a la entrada en vigor de la Ley 4/2007.

c) Descripción de los procedimientos de consulta internos y externos utilizados para la elaboración del plan de estudios, ya sea con profesionales, estudiantes u otros colectivos.

3. Objetivos, es decir, las competencias generales y específicas que los estudiantes deben adquirir durante sus estudios y que sean exigibles para otorgar el título correspondiente. Se deben garantizar, como mínimo, las competencias fijadas en los descriptores de Dublín ${ }^{6}$, así

6 De acuerdo con dichos descriptores, las competencias que indican la consecución del título de Grado se otorgan a los alumnos que:

hayan demostrado poseer y comprender conocimientos en un área de estudio que parte de la base de la educación secundaria general, y se suele encontrar a un nivel que, si bien se apoya en libros de texto avanzados, incluye también algunos aspectos que implican conocimientos procedentes de la vanguardia de su campo de estudio;

- sepan aplicar sus conocimientos a su trabajo o vocación de una forma profesional y posean las competencias que suelen demostrarse por medio de la elaboración y defensa de argumentos o la resolución de problemas dentro de su área de estudio;

- tengan la capacidad de reunir e interpretar datos relevantes (normalmente dentro de su área de estudio) para emitir juicios que incluyan una reflexión sobre temas relevantes de índole social, científica o ética;

- puedan transmitir información, ideas, problemas y soluciones a un público tanto especializado como no especializado; 
como aquellos otras que figuren en el Marco Español de Cualificaciones para la Educación Superior, MECES.

4. Acceso y admisión de estudiantes. En este apartado se debe incluir:

a) Sistemas accesibles de información previa a la matriculación y procedimientos accesibles de acogida y orientación de los estudiantes de nuevo ingreso para facilitar su incorporación a la Universidad y la enseñanza.

b) En su caso, condiciones o pruebas de acceso especiales, siempre autorizadas por la administración competente.

c) Sistemas de apoyo y orientación de los estudiantes, una vez matriculados.

d) Sistema propuesto por la universidad para la transferencia y reconocimiento de créditos.

- hayan desarrollado aquellas habilidades de aprendizaje necesarias para emprender estudios posteriores con un alto grado de autonomía.

Por su parte, las competencias que indican la consecución del título de Máster se otorgan a los alumnos que:

- hayan demostrado poseer y comprender conocimientos que se basan en los típicamente asociados al primer ciclo y los amplían y mejoran, lo que les aporta la base o posibilidad para ser originales en el desarrollo y/o aplicación de ideas, a menudo en un contexto de investigación;

- sepan aplicar los conocimientos adquiridos y su capacidad de resolución de problemas en entornos nuevos o poco conocidos dentro de contextos más amplios (o multidisciplinares) relacionados con su área de estudio;

- sean capaces de integrar conocimientos y enfrentarse a la complejidad de formular juicios a partir de una información que, siendo incompleta o limitada, incluya reflexiones sobre las responsabilidades sociales y éticas vinculadas a la aplicación de sus conocimientos y juicios;

- sepan comunicar sus conclusiones -y los conocimientos y razones últimas que las sustentan- a públicos especializados y no especializados de un modo claro y sin ambigüedades;

- posean las habilidades de aprendizaje que les permitan continuar estudiando de un modo que habrá de ser en gran medida autodirigido o autónomo.

Por último, las competencias que indican la consecución del título de Doctor se otorgan a los alumnos que:

- hayan demostrado una comprensión sistemática de un campo de estudio y el dominio de las habilidades y métodos de investigación relacionados con dicho campo;

- hayan demostrado la capacidad de concebir, diseñar, poner en práctica y adoptar un proceso sustancial de investigación con seriedad académica;

- hayan realizado una contribución a través de una investigación original que amplíe las fronteras del conocimiento desarrollando un corpus sustancial, del que parte merezca la publicación referenciada a nivel nacional o internacional;

- sean capaces de realizar un análisis crítico, evaluación y síntesis de ideas nuevas y complejas;

- sepan comunicarse con sus colegas, con la comunidad académica en su conjunto y con la sociedad en general acerca de sus áreas de conocimiento;

- se les suponga capaces de fomentar, en contextos académicos y profesionales, el avance tecnológico, social o cultural dentro de una sociedad basada en el conocimiento. 
5. Planificación de las enseñanzas, que deberá incluir:

a) Estructura de las enseñanzas: denominación del módulo o materia, contenido en créditos ECTS, organización temporal (semestral, trimestral, semanal...) y carácter obligatorio u optativo.

b) Descripción de los módulos o materias de enseñanza-aprendizaje que constituyen la estructura del plan de estudios, incluyendo las prácticas externas y el trabajo de fin de Grado o Máster: denominación, competencias que se adquieren, contenidos, actividades formativas con su contenido en créditos ECTS, metodología y relación con las competencias a adquirir y sistema de evaluación de la adquisición de competencias y de calificaciones.

c) Procedimientos para la organización de la movilidad de los estudiantes, incluyendo el sistema de reconocimiento y acumulación de créditos ECTS.

6. Personal académico, esto es, profesorado y otros recursos humanos necesarios y disponibles para llevar a cabo el plan de estudios propuesto, con indicación de su categoría académica, su vinculación a la universidad y su experiencia docente e investigadora o profesional.

7. Recursos materiales y servicios (espacios, instalaciones, laboratorios, equipamiento científico, técnico o artístico, biblioteca y salas de lectura, nuevas tecnologías, etc.), con justificación de que son adecuados para garantizar el desarrollo de las actividades formativas planificadas, observando los criterios de accesibilidad universal y diseño para todos. En el caso de que no se disponga de todos los recursos necesarios en el momento de la propuesta, se deberá indicar la previsión de su adquisición.

8. Resultados previstos, apartado donde se incluirá:

a) Estimación de las tasas de graduación, abandono y eficiencia ${ }^{7}$, así como su justificación.

$7 \quad$ Tasa de graduación es el porcentaje de estudiantes que finalizan la enseñanza en el tiempo previsto en el plan de estudios o en un año más respecto a su cohorte de entrada. Tasa de abandono se define como la relación porcentual entre el número total de estudiantes de una cohorte de nuevo ingreso que debieron obtener el título el año académico anterior y que no se han matriculado ni en ese año académico ni en el anterior. Tasa de eficiencia es la relación porcentual entre el número total de créditos teóricos del plan de estudios y el número total de créditos en los que han tenido que matricularse a lo largo de sus estudios el conjunto de estudiantes graduado en un determinado curso académico. 
b) Procedimiento general de la universidad para valorar el progreso y los resultados de aprendizaje de los estudiantes.

9. Sistema de garantía de calidad, que contendrá los siguientes elementos:

a) Responsables del sistema.

b) Procedimientos de evaluación y mejora de la calidad de la enseñanza y el profesorado.

c) Procedimientos para garantizar la calidad de las prácticas externas y los programas de movilidad.

d) Procedimientos de análisis de la inserción laboral de los graduados y de la satisfacción con la formación recibida.

e) Procedimiento para el análisis de la satisfacción de los distintos colectivos implicados (estudiantes, personal académico y de administración y servicios...) y de atención a las sugerencias o reclamaciones. Criterios específicos en el caso de extinción del título.

10. Calendario de implantación, indicando:

a) Cronograma de implantación del título.

b) Procedimiento de adaptación, en su caso, de los estudiantes de las titulaciones existentes al nuevo plan de estudios.

c) Enseñanzas que se extinguen por la implantación del título propuesto.

Una consecuencia inmediata del proceso descrito es la adaptación de los actuales planes de estudios a las directrices marcadas por la nueva normativa aprobada. Como punto de partida del diseño de nuevos títulos podemos considerar los denominados Libros Blancos surgidos del Programa de Convergencia Europea ${ }^{8}$ establecido por la Agencia Nacional de Evaluación de la Calidad y Acreditación (ANECA), ya que, tal y como recoge el Documento de trabajo elaborado por el Ministerio de Educación

\footnotetext{
${ }^{8}$ Con el fin de potenciar aquellas actuaciones que favorezcan la integración del sistema español de educación superior en el EEES, la ANECA ha desarrollado un conjunto de acciones, entre las que destaca la puesta en marcha de experiencias piloto de diseño e implantación de titulaciones, de las que han resultado los Libros Blancos.
} 
y Ciencia de 6 de noviembre de 2006, los trabajos realizados hasta este momento, entre los que se incluyen dichos Libros Blancos, tienen un gran valor, por el alto grado de consenso que les acompaña y la extensa información que contienen.

Los Libros Blancos muestran el resultado del trabajo realizado por una red de universidades españolas, apoyadas por la Agencia, con el fin de diseñar títulos de Grado adaptados al EEES, recogiendo aspectos tales como el análisis de los estudios correspondientes o afines en Europa, características de la titulación europea seleccionada, estudios de inserción laboral de los titulados durante el último quinquenio o perfiles y competencias profesionales requeridas, así como diversos aspectos relevantes para el diseño de los nuevos títulos (contenidos generales, valoración del número de horas de trabajo del estudiante en relación con dichos contenidos y su asignación de créditos ECTS...).

Para llevar a cabo el diseño de los nuevos títulos, la ANECA ha presentado varias convocatorias de ayudas, con el objetivo de poner a disposición de las universidades los recursos financieros necesarios para la realización de los estudios. Como resultado de las tres convocatorias presentadas hasta este momento, se han desarrollado más de cincuenta proyectos de nuevas titulaciones adaptadas al EEES. De los proyectos resultantes, dado el objeto de nuestro estudio, nos vamos a referir a aquellos Libros Blancos relativos a títulos de Grado que podemos considerar equivalentes a las titulaciones actuales de carácter económico-empresarial, esto es, los títulos de Grado en Economía y Empresa.

\subsection{Los estudios de economía y empresa en el EEES}

Dentro de la II Convocatoria de Ayudas para el diseño de planes de estudio y títulos de Grado presentada por la ANECA, la CONFEDE (Conferencia Española de Decanos de Economía y Empresa) solicitó, en noviembre de 2003, el Proyecto para los Estudios de Grado en Economía y Empresa, que fue concedido en diciembre de ese año. El resultado del trabajo realizado, en el que participaron 55 universidades españolas, públicas y privadas, fue el Libro Blanco del Título de Grado en Economía y Empresa, publicado en junio de 2005. En el Libro Blanco se propone una estructura general para los títulos, además de analizar la situación actual de los estudios de economía y empresa en Europa y en España, así como la inserción laboral de los titulados, identificando perfiles y competencias profesionales. 
De La Sorbona a Londres: El camino hacia el Espacio Europeo de Educación Superior (Adaptación en España: especial referencia a los Estudios Económico-Empresariales)

Por lo que se refiere a los objetivos de los títulos, se establece como objetivo central del título de Grado en ECONOMía el de formar profesionales capaces de desempeñar labores de gestión, asesoramiento y evaluación en los asuntos económicos en general. Esas labores se pueden desarrollar en el ámbito privado o en el público, en la empresa o en cualquier otra institución de relevancia económica y social. El Graduado debe conocer el funcionamiento y las consecuencias de los sistemas económicos, de las distintas alternativas de asignación de recursos, de acumulación de riqueza y de distribución de la renta y estar en condiciones de contribuir a su buen funcionamiento y mejora. En concreto, debe ser capaz de identificar y anticipar los problemas económicos relevantes en cualquier situación concreta, de discutir las alternativas que facilitan su resolución de seleccionar las más adecuadas a los objetivos y de evaluar los resultados a los que conduce.

En cuanto al título de Grado en EMPRESA, el objetivo general es formar profesionales capaces de desempeñar labores de gestión, asesoramiento y evaluación en las organizaciones productivas. Esas labores se pueden desarrollar en el ámbito global de la organización o en cualquiera de sus áreas funcionales: producción, recursos humanos, financiación, comercialización, inversión, administración o contabilidad. El Graduado debe conocer la articulación del normal desenvolvimiento de todas estas áreas funcionales con los objetivos generales de la unidad productiva, de éstos con el contexto global de la economía y estar en condiciones de contribuir con su actividad al buen funcionamiento y a la mejora de resultados. En concreto, debe saber identificar y anticipar oportunidades, asignar recursos, organizar la información, seleccionar y motivar a las personas, tomar decisiones, alcanzar objetivos propuestos y evaluar resultados.

Con respecto a la estructura general de los títulos, se acordó que el porcentaje de contenidos formativos comunes fuera idéntico en ambos Grados y tuviera el valor de dos tercios, es decir, el $66,67 \%$, y que el resto, un 33,33\%, fuera propio de cada Universidad. Este porcentaje de contenidos comunes equivale a 160 créditos de troncalidad $^{9}$, con lo que se garantiza una formación mínima común, permitiendo a las diferentes

9 Para el caso de un grado de cuatro años y 240 créditos, ya que es la estructura establecida para los títulos de grado en nuestro país, aunque en el Libro Blanco, publicado antes de las directrices generales del MEC, también contiene el diseño de titulaciones de 180 créditos $y$, por consiguiente, tres años de duración. 
universidades adaptar el título y la forma de impartirlo a sus realidades y preferencias.

Para la determinación de los contenidos comunes e instrumentales obligatorios se siguieron las recomendaciones de la ANECA, identificándose 8 ó 9 bloques temáticos, donde un bloque temático no es una asignatura y podrá ser posteriormente diversificado en asignaturas concretas y organizado temporalmente a lo largo de la titulación por cada universidad.

Los bloques temáticos correspondientes a los Grados de Economía y Empresa se recogen en las Tablas 3 y 4.

Tabla 3: Bloques temáticos y contenidos formativos mínimos para el Grado en Empresa

\begin{tabular}{|c|c|}
\hline Bloque temático & Contenidos formativos mínimos \\
\hline Contabilidad & $\begin{array}{l}\text { Contabilidad financiera } \\
\text { Contabilidad de Gestión } \\
\text { Análisis y consolidación contable } \\
\text { Auditoría }\end{array}$ \\
\hline Organización de Empresas & $\begin{array}{l}\text { Organización y Diseño } \\
\text { Dirección Estratégica } \\
\text { Dirección de Producción/Operaciones } \\
\text { Dirección de Recursos Humanos } \\
\end{array}$ \\
\hline Finanzas & $\begin{array}{l}\text { Valoración de activos y Análisis de inversiones } \\
\text { Decisiones de financiación } \\
\text { Análisis y planificación financiera } \\
\text { Matemática Financiera }\end{array}$ \\
\hline Comercialización e Investigación de Mercados & $\begin{array}{l}\text { Dirección Comercial } \\
\text { Investigación comercial }\end{array}$ \\
\hline Entorno económico y marco jurídico & $\begin{array}{l}\text { Economía Española y Mundial } \\
\text { Régimen fiscal de la empresa } \\
\text { Políticas Económicas } \\
\text { Derecho de la empresa }\end{array}$ \\
\hline Análisis Económico & $\begin{array}{l}\text { Microeconomía } \\
\text { Macroeconomía }\end{array}$ \\
\hline Métodos cuantitativos para la empresa & $\begin{array}{l}\text { Matemáticas } \\
\text { Estadística } \\
\text { Econometría }\end{array}$ \\
\hline
\end{tabular}

Fuente: Libro Blanco (ANECA 2005).

Una vez identificados los bloques temáticos y contenidos formativos que debe incluir el título, se determinaron los pesos específicos aplicables a cada una de ellos. Los criterios para la fijación de los porcentajes han sido ligeramente distintos en ambos grados. En el Grado de Empresa se acordó que el conjunto de los bloques temáticos directamente relacionados con la empresa debería tener un peso mínimo, 
establecido en el 57,5\% del total de la troncalidad, debiendo dividirse en partes iguales entre Contabilidad + Finanzas, y Organización de Empresas + Comercialización e Investigación de Mercados. En el caso del Grado en Economía, no se realizó ningún reparto previo, sino que se trabajó para cada bloque temático. En ambos casos se tomó como referencia la troncalidad contenida en el Decreto de Directrices Generales Propias del año 90 y una estimación de la troncalidad más la obligatoriedad establecida por las Universidades.

Tabla 4: Bloques temáticos y contenidos formativos mínimos para el Grado en Economía

\begin{tabular}{|l|l|}
\hline \multicolumn{1}{|c|}{ Bloque temático } & Contenidos formativos mínimos \\
\hline Análisis Económico & $\begin{array}{l}\text { Microeconomía } \\
\text { Macroeconomía }\end{array}$ \\
\hline Economía del Sector Público & $\begin{array}{l}\text { Economía pública } \\
\text { Sistema Fiscal }\end{array}$ \\
\hline \multirow{3}{*}{ Economía Española, Internacional y Sectorial } & $\begin{array}{l}\text { Economía Española y Mundial } \\
\text { Economía Internacional } \\
\text { Economía e Instituciones financieras } \\
\text { Políticas instrumentales } \\
\text { Políticas Territoriales y sectoriales }\end{array}$ \\
\hline \multirow{2}{*}{ Entorno empresarial } & $\begin{array}{l}\text { Economía de la empresa (Organización de } \\
\text { Empresas, Comercialización e Inv. Mercados y }\end{array}$ \\
\hline \multirow{2}{*}{ Métodos cuantitativos para la economía } & $\begin{array}{l}\text { Finanzas Empresariales) } \\
\text { Contabilidad }\end{array}$ \\
\hline \multirow{2}{*}{ Historia Económica y marco jurídico } & $\begin{array}{l}\text { Matemáticas } \\
\text { Estadística } \\
\text { Econometría }\end{array}$ \\
\hline
\end{tabular}

Fuente: Libro Blanco (ANECA 2005).

A la hora de establecer una relación entre los créditos BOE (presenciales) con los créditos ECTS se determinó, teniendo en cuenta el Informe elaborado por la Red Piloto de la Comunidad de Madrid para la Licenciatura en Administración y Dirección de Empresas, la siguiente estimación:

- 1 hora de clase de teoría da lugar a 2 horas de trabajo del alumno.

- 1 hora de clase de práctica da lugar a 1 hora de trabajo del alumno.

- 1 crédito ECTS supone 25 horas de trabajo del alumno. 
Por tanto:

- 1 crédito BOE o presencial son 10 horas de clase.

- 1 crédito ECTS son 25 horas de trabajo = 10 horas presenciales + 15 horas no presenciales.

Las Tablas 5 y 6 presentan la distribución de los contenidos formativos y asignación de créditos europeos para los dos Grados, teniendo en cuenta la duración de 4 años y 240 créditos ECTS, aunque, como ya hemos señalado, el Libro Blanco también recoge la estructura de 180 créditos.

Tabla 5: Distribución de créditos para el Grado en Empresa

\begin{tabular}{|c|c|c|c|c|c|c|c|}
\hline \multirow[t]{2}{*}{ Bloque temático } & \multirow[t]{2}{*}{ Peso $(\%)$} & \multirow{2}{*}{$\begin{array}{c}\mathrm{N}^{0} \text { mínimo } \\
\text { de créditos } \\
\text { ECTS }\end{array}$} & \multicolumn{5}{|c|}{$\begin{array}{l}\text { Distribución de las horas } \\
\text { de trabajo del estudiante }\end{array}$} \\
\hline & & & $\% \mathrm{P}$ & $T^{\mathrm{a}}$ & $\mathbf{P}^{\mathbf{a}}$ & T.P. & Tut. \\
\hline Contabilidad & 15 & 24 & 0,40 & $1 / 2$ & $1 / 2$ & 0,85 & 0,15 \\
\hline Organización de Empresas & 16,25 & 26 & 0,40 & $1 / 2$ & $1 / 2$ & 0,85 & 0,15 \\
\hline Finanzas & 13,75 & 22 & 0,40 & $1 / 2$ & $1 / 2$ & 0,85 & 0,15 \\
\hline $\begin{array}{l}\text { Comercialización e } \\
\text { Investigación de Mercados }\end{array}$ & 12,5 & 20 & 0,40 & $1 / 2$ & $1 / 2$ & 0,85 & 0,15 \\
\hline $\begin{array}{l}\text { Entorno económico y marco } \\
\text { jurídico }\end{array}$ & 15 & 24 & 0,375 & $2 / 3$ & $1 / 3$ & 0,85 & 0,15 \\
\hline Análisis Económico & 12,5 & 20 & 0,375 & $2 / 3$ & $1 / 3$ & 0,85 & 0,15 \\
\hline $\begin{array}{l}\text { Métodos cuantitativos para la } \\
\text { empresa }\end{array}$ & 15 & 24 & 0,40 & $1 / 2$ & $1 / 2$ & 0,85 & 0,15 \\
\hline TOTAL & 100 & 160 & & & & & \\
\hline
\end{tabular}

Fuente: Libro Blanco (ANECA 2005).

Tabla 6: Distribución de créditos para el Grado en Economía

\begin{tabular}{|l|c|c|c|c|c|c|c|}
\hline \multirow{2}{*}{\multicolumn{1}{c|}{ Bloque temático }} & \multirow{2}{*}{$\begin{array}{c}\text { No mínimo } \\
\text { de créditos }\end{array}$} & \multicolumn{5}{c|}{$\begin{array}{c}\text { Distribución de las horas } \\
\text { de trabajo del estudiante }\end{array}$} \\
\cline { 7 - 10 } & & ECTS & \% P & $\mathbf{T}^{\mathbf{a}}$ & $\mathbf{P}^{\mathbf{a}}$ & T.P. & Tut. \\
\hline Análisis Económico & 15 & 40 & 0,375 & $2 / 3$ & $1 / 3$ & 0,85 & 0,15 \\
\hline Economía del Sector Público & 16,25 & 12 & 0,375 & $2 / 3$ & $1 / 3$ & 0,85 & 0,15 \\
\hline $\begin{array}{l}\text { Economía Española, } \\
\text { Internacional y Sectorial }\end{array}$ & 13,75 & 32 & 0,375 & $2 / 3$ & $1 / 3$ & 0,85 & 0,15 \\
\hline Entorno empresarial & 12,5 & 24 & 0,40 & $1 / 2$ & $1 / 2$ & 0,85 & 0,15 \\
\hline Métodos cuantitativos & 15 & 36 & 0,40 & $1 / 2$ & $1 / 3$ & 0,85 & 0,15 \\
\hline $\begin{array}{l}\text { Historia Económica y marco } \\
\text { jurídico }\end{array}$ & 12,5 & 16 & 0,375 & $2 / 3$ & $1 / 3$ & 0,85 & 0,15 \\
\hline TOTAL & 100 & 60 & & & & & \\
\hline
\end{tabular}

Las horas de trabajo del estudiante se reparten entre $\mathrm{P}=$ Presenciales (de $\mathrm{T}^{\mathrm{a}}=$ Teoría y $\mathrm{P}^{\mathrm{a}}=$ =Práctica) y no presenciales:

T.P. $=$ Trabajo personal y Tut. $=$ Tutorías.

Fuente: Libro Blanco (ANECA 2005). 


\section{CONCLUSIONES}

Uno de los grandes retos que deben afrontar en la actualidad las instituciones de educación superior a nivel europeo es su plena integración en el Espacio Europeo de Educación Superior, con el fin de favorecer la libre circulación de estudiantes y titulados entre los distintos países miembros.

El proceso de convergencia europea descansa sobre tres pilares básicos: el establecimiento de una estructura de titulaciones en dos ciclos principales (Grado y Máster), la adopción de un sistema común de créditos basados en el trabajo y aprendizaje del estudiante (sistema ECTS) y el desarrollo de procedimientos de acreditación y aseguramiento de la calidad. Todo ello centrado en la máxima transparencia, a través de documentos normalizados comprensibles y comparables (Suplemento Europeo al Título), tal como se recoge en la Figura 3.

Figura 3: Claves del proceso de convergencia europea

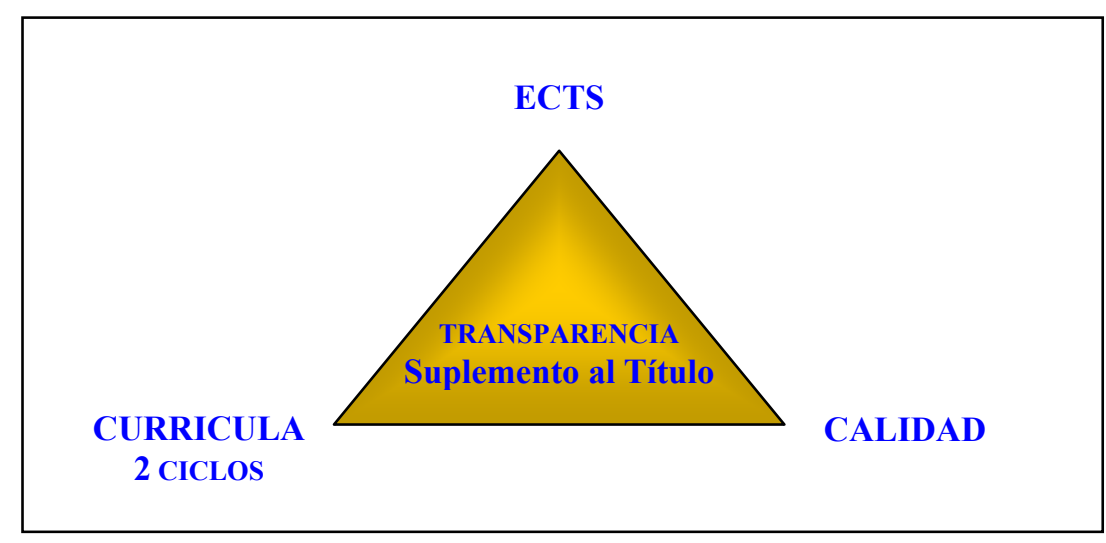

Fuente: Corcuera y Pagani (2002)

No obstante, los cambios que trae consigo la armonización europea en educación superior no serán de la misma magnitud en todos los países implicados, puesto que hay determinados países, sobre todo del norte de Europa, cuyos sistemas educativos ya se acercan bastante a la concepción de aprendizaje centrado en el estudiante que propugna el proceso de Bolonia. En contraposición, países como España e Italia, con sistemas basados tradicionalmente en la lección magistral, tendrán que enfrentarse a mayores retos a la hora de adaptarse a las nuevas metodologías. Por otro lado, siendo uno de los objetivos del EEES la total 
circulación de universitarios, en razón del establecimiento de sistemas que facilitan el reconocimiento y transferencia de créditos, la existencia de dificultades lingüísticas por parte de estudiantes de algunos de estos países, como el nuestro, supondrá un obstáculo para el pleno desarrollo del EEES.

En el caso de España, el proceso de adaptación al EEES supone asimismo una gran oportunidad para modificar algunos de los problemas con los que en la actualidad funciona la universidad, entre los que podemos citar los siguientes: escaso desarrollo de la atención personalizada hacia el alumno, predominio de la lección magistral como metodología docente o escasa preparación pedagógico-didáctica del profesorado, aspectos éstos quizá motivados por el bajo reconocimiento de la labor docente frente a la investigadora; escasa movilidad de estudiantes y personal, lo que incrementa el problema del bajo nivel de conocimiento de idiomas extranjeros; dificultad de implicar a los estudiantes en sus propios procesos formativos 0 inadecuación de infraestructuras $y$ equipamientos, fijados para clases magistrales y grupos numerosos.

Por todo lo anterior, la adaptación del sistema universitario español al proceso de convergencia europea en educación superior no debe limitarse a la adecuación del número de créditos actuales a los ECTS o a la denominación de las titulaciones, cuyo diseño debe responder a las necesidades reales de los estudiantes y la sociedad.

Junto al desarrollo de las directrices relativas a la organización de las enseñanzas, con el fin de adaptarse a la normativa emanada del proceso de Bolonia, deben acometerse innovaciones de fondo, sobre todo, en cuanto a las metodologías docentes. Además de propiciar y apoyar cambios profundos en los planes de estudio y los programas de las asignaturas para incorporar los principios y procedimientos del EEES, es preciso procurar un cambio de actitud y de mentalidad; por un lado, en el profesorado, a fin de que supere su resistencia al cambio metodológico y mejore su formación didáctica, incrementando también el grado de colaboración en docencia; por otro, en el estudiante, que debe implicarse en la toma de decisiones, evaluando sus necesidades formativas y definiendo itinerarios educativos, y tomar una postura activa y participativa, lo que supone, a su vez, reforzar su formación práctica, mediante prácticas externas y en el aula (laboratorios, seminarios, trabajos), buscando la armonización entre la orientación teórico-científica y la orientación técnico-práctica. Para lograr esta armonización es necesario que exista un equilibrio entre la enseñanza presencial y el trabajo personal del estudiante 
fuera del aula, que es dirigido y supervisado por el profesor en su labor de tutor.

En todo caso, hay que tener en cuenta que no existe una línea homogénea en las universidades europeas, sino que destaca la heterogeneidad entre países, lo que implica que el desarrollo del proceso no sea unívoco. Además, existen ciertas reticencias por parte de universidades de los cinco grandes países (Alemania, Francia, Italia, Reino Unido, dada la diversidad de la enseñanza universitaria actual en las cuatro naciones que lo componen y, por supuesto, España), lo que puede suponer un obstáculo para la plena convergencia.

A esto hay que añadir la necesidad de disponer de los recursos económicos suficientes para garantizar el cumplimiento de los objetivos propuestos con racionalidad y eficacia. El proceso exige la inversión en infraestructuras, que faciliten el cambio de una educación centrada en la enseñanza (profesor) a otra centrada en el aprendizaje (alumno). Además, para garantizar la igualdad de oportunidades y el fomento de la movilidad es preciso implantar un sistema de becas y ayudas al estudio, para lo que se exige financiación. Esta búsqueda de recursos puede traer consigo un enfrentamiento entre universidades públicas y privadas, debiendo las primeras recibir una atención especial de los Ministerios de Educación.

\section{BIBLIOGRAFÍA}

Agencia Nacional de Evaluación de la Calidad y Acreditación (2005) Libro Blanco del Título de Grado en Economía y en Empresa [http://www.a neca.es/activin/docs/libroblanco_economia_def.pdf (consultado el 02 11/2007)].

Carta Magna de las Universidades Europeas (1988), Bolonia, 18 de septiembre de 1988 [www.crue.org/cmue.htm (consultado el 19/10/ 2007)].

Comisión Europea (1997) Por una Europa del conocimiento. Bruselas, 12 de noviembre de 1997. COM (97) 563, Boletín UE 11-1997.

Comunicado de Bergen (2005), Bergen, 19-20 de mayo de 2005 [http://w ww.eees.ua.es/documentos/Bergen_Comunicado-esp.pdf (consultado el 23/10/2007)]. 
Comunicado de Berlín (2003), Berlín, 19 de septiembre de 2003 [http://www.eees.ua.es/documentos/Berlin_esp.pdf (consultado el 23 10/2007)].

Comunicado de Londres (2007), Londres, 18 de mayo de 2007 [http://www.mec.es/universidades/eees/files/2007-comunicado-de-la -cumbre.pdf (consultado el 25/10/2007)].

- [http://www.mec.es/universidades/eees/files/2007-comunicado-londr es.pdf (consultado el 25/10/2007)].

Comunicado de Praga (2001), Praga, 19 de mayo de 2001 [http://www.e ees.ua.es/documentos/declaracion\%20praga.pdf (consultado el 23 10/2007)].

Consejo de Coordinación Universitaria (2006) Informe del Consejo de Coordinación Universitaria al Documento de Trabajo "La organización de las enseñanzas universitarias en España" (Sesión de 14 de noviembre de 2006) [http://www.mec.es/educa/ccuniv/html/docume ntos/Informe_CCU.pdf (consultado el 7/11/2007].

- (2006) Propuestas para la Renovación de las Metodologías Educativas en la Universidad [http://www.mec.es/educa/ccuniv/html/metodolo gias/docu/PROPUESTA_RENOVACION.pdf (consultado el 10/11/2007)].

- (2007) Financiación del Sistema Universitario Español. Informe [http://www.mec.es/educa/ccuniv/html/documentos/Financiacion.pdf (consultado el 10/11/2007)].

Convenio sobre reconocimiento de cualificaciones relativas a la Educación Superior en la región europea (1997), Lisboa [http://conventions.coe. int/Treaty/FR/Treaties/Html/165-SPA.htm (consultado el 23/10/2007)].

CORCUERA F. y R. Pagani (2002) Los Créditos ECTS. Jornadas de la CRUE: La gestión académica ante el nuevo reto del Espacio Europeo de Educación Superior. Vigo, 4 y 5 de noviembre de 2002 [http://www. unizar.es/eees/jornadas/El\%20credito\%20europeo_Fidel\%20CORCUERA. pdf (consultado el 7/11/2007)].

Declaración de Bolonia (1999), Bolonia, 19 de junio de 1999 [http://www.crue.org/apadsisuniv.htm (consultado el 19/10/2007)].

Declaración de La Sorbona (1998), París, 25 de mayo de 1998 [http:// www.eees.ua.es/documentos/declaracion_sorbona.htm (consultado el 19/10/2007)].

Directiva 2005/36/CE del Parlamento Europeo y del Consejo, de 7 de septiembre de 2005, relativa al reconocimiento de cualificaciones profesionales. 
García SuÁreZ, J.A. (2006) ¿Qué es el Espacio Europeo de Educación Superior? El reto de Bolonia. Preguntas y respuestas. Barcelona: Publicacions i Edicions de la Universitat de Barcelona.

Ley Orgánica 6/2001, de 21 de Diciembre, de Universidades (B.O.E. n 307 de 24 de diciembre).

Ley Orgánica 4/2007, de 12 de abril, por la que se modifica la Ley Orgánica 6/2001, de 21 de Diciembre, de Universidades (B.O.E. n 89 de 13 de abril).

MANZANO, V. y L.A. ZAMBRANO (2007) El diseño de la nueva universidad europea. Alguna causa, algunas consecuencias. Sevilla: Atrapasueños Editorial.

MiCHAVILA, F. y B. CALVo (2000) La Universidad Española hacia Europa. Ed.: Fundación Alfonso Martín Escudero.

Ministerio de Educación, Cultura y Deporte (2003) La integración del sistema universitario español en el Espacio Europeo de Educación Superior. Documento-Marco [http://www.mec.es/universidades/eees/ files/Documento_Marco.pdf (consultado el 6/11/2007)].

Ministerio de Educación y Ciencia (2006a) La organización de las enseñanzas universitarias en España. Documento de trabajo [http://www.mec.es/ educa/ccuniv/html/documentos/Propuesta.pdf (consultado el 7 11/2007)].

- (2006b) Aclaraciones sobre el documento de 26 de septiembre de 2006 "La organización de las enseñanzas universitarias en España". Documento de trabajo [http://www.mec.es/educa/ccuniv/html/documentos/Acla raciones.pdf (consultado el 7/11/2007)].

- (2006c) Directrices para la elaboración de títulos universitarios de Grado y Máster. Documento de trabajo [http://www.mec.es/educa/ ccuniv/html/documentos/Directrices_para_la_elaboracion_de_titulos.pdf (consultado el 7/11/2007)].

- (2007a) Materias básicas por ramas. Anexo del documento de Directrices para la elaboración de títulos universitarios de Grado y Máster. Documento de trabajo [http://www.mec.es/educa/ccuniv/html/docu mentos/Materias.pdf (consultado el 7/11/2007)].

- (2007b) Resolución de 17 de diciembre de 2007, de la Secretaría de Estado de Universidades e Investigación, por la que se publica el Acuerdo de Consejo de Ministros de 14 de diciembre de 2007, por el que se establecen las condiciones a las que deberán adecuarse los planes de estudios conducentes a la obtención de títulos que habiliten 
para el ejercicio de la profesión regulada de Arquitecto. (B.O.E. $\mathrm{n}^{\circ}$ 305 de 21 de diciembre).

- (2007c) Resolución de 17 de diciembre de 2007, de la Secretaría de Estado de Universidades e Investigación, por la que se publica el Acuerdo de Consejo de Ministros de 14 de diciembre de 2007, por el que se establecen las condiciones a las que deberán adecuarse los planes de estudios conducentes a la obtención de títulos que habiliten para el ejercicio de la profesión regulada de Arquitecto Técnico. (B.O.E. $n^{\circ} 305$ de 21 de diciembre).

- (2007d) Resolución de 17 de diciembre de 2007, de la Secretaría de Estado de Universidades e Investigación, por la que se publica el Acuerdo de Consejo de Ministros de 14 de diciembre de 2007, por el que se establecen las condiciones a las que deberán adecuarse los planes de estudios conducentes a la obtención de títulos que habiliten para el ejercicio de la profesión regulada de Maestro en Educación Infantil. (B.O.E. $\mathrm{n}^{\circ} 305$ de 21 de diciembre).

- (2007e) Resolución de 17 de diciembre de 2007, de la Secretaría de Estado de Universidades e Investigación, por la que se publica el Acuerdo de Consejo de Ministros de 14 de diciembre de 2007, por el que se establecen las condiciones a las que deberán adecuarse los planes de estudios conducentes a la obtención de títulos que habiliten para el ejercicio de la profesión regulada de Maestro en Educación Primaria. (B.O.E. $\mathrm{n}^{\circ} 305$ de 21 de diciembre).

- (2007f) Resolución de 17 de diciembre de 2007, de la Secretaría de Estado de Universidades e Investigación, por la que se publica el Acuerdo de Consejo de Ministros de 14 de diciembre de 2007, por el que se establecen las condiciones a las que deberán adecuarse los planes de estudios conducentes a la obtención de títulos que habiliten para el ejercicio de la profesión regulada de Médico. (B.O.E. $\mathrm{n}^{\circ} 305$ de 21 de diciembre).

- (2007g) Resolución de 17 de diciembre de 2007, de la Secretaría de Estado de Universidades e Investigación, por la que se publica el Acuerdo de Consejo de Ministros de 14 de diciembre de 2007, por el que se establecen las condiciones a las que deberán adecuarse los planes de estudios conducentes a la obtención de títulos que habiliten para el ejercicio de la profesión regulada de Profesor de Educación Secundaria Obligatoria y Bachillerato, Formación Profesional y Enseñanzas de Idiomas. (B.O.E. $\mathrm{n}^{\circ} 305$ de 21 de diciembre).

- (2007h) Resolución de 17 de diciembre de 2007, de la Secretaría de Estado de Universidades e Investigación, por la que se publica el Acuerdo de Consejo de Ministros de 14 de diciembre de 2007, por el 
que se establecen las condiciones a las que deberán adecuarse los planes de estudios conducentes a la obtención de títulos que habiliten para el ejercicio de la profesión regulada de Veterinario. (B.O.E. $n^{\circ}$ 305 de 21 de diciembre).

Organización de las Naciones Unidas para la Educación, la Ciencia y la Cultura (1998) "La educación superior en el siglo XXI: Visión y acción". Conferencia Mundial sobre la Educación Superior, París: 5 a 9 de octubre de 1998.

Real Decreto 1044/2003, de 1 de agosto, por el que se establece el procedimiento para la expedición por las universidades del Suplemento Europeo al Título (B.O.E. $\mathrm{n}^{\circ} 218$ de 11 de septiembre).

Real Decreto 1125/2003, de 5 de septiembre, por el que se establece el sistema europeo de créditos y el sistema de calificaciones en las titulaciones universitarias de carácter oficial y validez en todo el territorio nacional (B.O.E. $\mathrm{n}^{\circ} 224$ de 18 de septiembre).

Real Decreto 49/2004, de 19 de enero, sobre homologación de planes de estudios y títulos de carácter oficial y validez en todo el territorio nacional (B.O.E. $\mathrm{n}^{\circ} 19$ de 22 de enero).

Real Decreto 285/2004, de 20 de febrero, por el que se regulan las condiciones de homologación y convalidación de títulos y estudios extranjeros de educación superior (B.O.E. $\mathrm{n}^{\circ} 55$ de 4 de marzo).

Real Decreto 55/2005, de 21 de enero, por el que se establece la estructura de las enseñanzas universitarias y se regulan los estudios universitarios oficiales de Grado (B.O.E. $\mathrm{n}^{\circ} 21$ de 25 de enero).

Real Decreto 56/2005, de 21 de enero, por el que se regulan los estudios universitarios oficiales de Posgrado (B.O.E. $\mathrm{n}^{\circ} 21$ de 25 de enero).

Real Decreto $1509 / 2005$, de 16 de diciembre, por el que se modifican el Real Decreto 55/2005, de 21 de enero, por el que se establece la estructura de las enseñanzas universitarias y se regulan los estudios universitarios oficiales de grado y el Real Decreto 56/2005, de 21 de enero, por el que se regulan los estudios universitarios oficiales de posgrado (B.O.E. $n^{\circ} 303$ de 20 de diciembre).

Real Decreto 189/2007, de 9 de febrero, por el que se modifican determinadas disposiciones del Real Decreto 56/2005, de 21 de enero, por el que regulan los estudios universitarios oficiales de Posgrado (B.O.E. $n^{\circ} 36$ de 10 de febrero).

Real Decreto 1393/2007, de 29 de octubre, por el que se establece la ordenación de las enseñanzas universitarias oficiales (B.O.E. $n^{\circ} 260$ de 30 de octubre). 